\title{
A Ludicidade como Importante Estratégia de Ensino no PNAIC - Pacto Nacional pela Alfabetização na Idade Certa, em Juazeiro-BA
}

\author{
Geisa Gabriele Santos ${ }^{1}$; Livia Suilan Rosa Caffé ${ }^{2}$ Hesler Piedade Caffé Filho ${ }^{3}$
}

\begin{abstract}
Resumo: Esse trabalho visa estabelecer um diálogo acadêmico entre a gestão estratégica, gestão de políticas públicas e elementos do PNAIC - Pacto Nacional pela Alfabetização na Idade Certa. O objetivo dessa produção é verificar a possibilidade da utilização da ludicidade na alfabetização em uma escola pública municipal, realizando uma revisão bibliográfica sobre estratégias contidas no Plano Nacional da Educação, entendendo como esses elementos se interagem sob a luz das políticas públicas e realizando uma experiência em uma escola da Rede municipal de ensino, na cidade de Juazeiro-BA. Para isso, buscou-se um referencial teórico que versasse nas linhas da gestão estratégica, gestão de políticas públicas, alfabetização e ludicidade. O método da pesquisa foi bibliográfico e estudo de caso. Verificou-se, no campo da pesquisa, que a ludicidade é fundamental para a condição de motivação na aprendizagem, que os jogos tem um grande papel no processo da alfabetização sem esquecer da importância de planejar atividades que atendam a todos os alunos, cada um dentro da sua necessidade pessoal e específica. Os autores sugerem ao final do estudo, que além de outros anos e modalidades de ensino da mesma instituição educacional, outras escolas e ambientes educacionais possam fazer uso e/ou potencializar essa importante estratégia de ensino.
\end{abstract}

Palavras chaves: PNAIC, Ludicidade, Gestão Estratégica.

\section{The Playfulness as Essencial Education Strategy in PNAIC - National Pact for Literacy in the Right Age in Juazeiro-BA}

\begin{abstract}
This work aims to establish an academic dialogue between strategic management, public policy and management elements of PNAIC - National Pact for Literacy in the Age One. The purpose of this production is to check the possibility of using playfulness in literacy in a public school, conducting a literature review on strategies contained in the National Education Plan, understanding how these elements interact in the light of public policies and conducting an experiment in a school municipal education network in the city of JuazeiroBA. For this, we sought a theoretical framework which would deal in the lines of strategic management, public policy, literacy and playfulness. The research method was literature and case study. It was found in the field of research, the playfulness is key to motivation condition in the learning, the games have a big role in the literacy process without forgetting the importance of planning activities that meet all students, each within your personal and specific needs. The authors suggest the end of the study, in addition to other years and teaching modalities of the same educational institution, other schools and educational environments can make use of and / or enhance this important teaching strategy.
\end{abstract}

Key words: PNAIC, Playfulness, Strategic Management .

\footnotetext{
${ }^{1}$ Especialista em Gestão de Recursos Humanos pela UPE - Universidade de Pernambuco Campus Petrolina. Assessora de Formação Secretaria Municipal de Educação de Juazeiro BA e Orientadora de Estudos do PNAIC. Estudante do Curso de Especialização em Gestão Pública da UNIVASF. E-mail geisa_gabrielle@hotmail.com

${ }^{2}$ Graduada em Pedagogia pela UNEB - Universidade Estadual da Bahia Campus Juazeiro. Professora do Ensino Fundamental I - Secretaria Municipal de Educação de Juazeiro BA. Estudante do Curso de Especialização em Gestão Empresarial da FASJ. E-mail: liviasuil@bol.com.br

${ }^{3}$ Mestre em Gestão de Políticas Públicas - UFRB - Universidade do Recôncavo Baiano. Administrador na UNIVASF - Universidade Federal do Vale do São Francisco. Professor da Pós Graduação em Gestão Pública - UNIVASF. Professor de Pós Graduação em Gestão Estratégica - FASJ - Faculdade São Francisco de Juazeiro. E-mail: hesler.caffe@ univasf.edu.br
} 
Id on Line Revista Multidisciplinar e de Psicologia

Id on Line Revista Multidisciplinar e de Psicologia

\section{Introdução}

O Pacto Nacional pela Alfabetização na Idade Certa - PNAIC é parte integrante de um conjunto de Políticas educacionais para a erradicação do analfabetismo e para a plena garantia dos direitos de aprendizagem nas séries do $1^{\circ}, 2^{\circ}$ e $3^{\circ}$ ano do Ensino Fundamental, ciclo este de alfabetização dos educandos, em que compreende-se que este, exerce grande importância na formação de cidadãos críticos e conscientes do seu papel na sociedade, capazes de intervir e contribuir para uma sociedade mais justa e igualitária. A educação, sendo a "mola propulsora" da humanidade, deve primar por ofertar condições dignas da ascensão desses "pequenos cidadãos".

Diante da Proposta Pedagógica da Rede Municipal de Ensino de Juazeiro - BA em consonância com as resoluções que regem o Pacto, o município citado tem o desafio de fazer a fusão dos objetivos que deverão por sua vez, proporcionar uma melhor qualidade educacional nas séries do ciclo de alfabetização, uma vez que foi firmada no ano de 2012 a parceria entre o Governo Federal, através do MEC e a Prefeitura Municipal, através da Secretaria de Educação da cidade.

Sendo o eixo principal do PNAIC, a Formação continuada, os Professores alfabetizadores têm momentos de estudos dos quais foram definidos conteúdos que em muito vem a somar na discussão acerca dos direitos de aprendizagem dos educandos no ciclo de alfabetização, processos avaliativos e acompanhamento da aprendizagem dessas crianças, além de contribuir para o planejamento de situações didáticas e conhecimento e a utilização dos materiais distribuídos pelo MEC com o objetivo da melhoria da qualidade do ensino público. Tendo portanto, essas ações de cunho formativo, o respaldo na Política Nacional de Formação de Profissionais do Magistério da Educação Básica, através do Decreto de $\mathrm{N}^{\circ}$ 6.755, de 29 de janeiro de 2009.

Alfabetizar letrando é sem dúvidas a grande meta na contemporaneidade, tanto de Redes públicas de ensino, como de Redes particulares, e o PNAIC nesse sentido, assume esse compromisso ao instituir as metas a serem alcançadas na sua execução em regime de parceria com os municípios e estados do país.

Atualmente, a Rede Municipal de Juazeiro - BA conta 09 orientadores de estudos que por sua vez, recebem a Formação Continuada da Instituição de Ensino Superior - IES parceira do MEC e através da junção das propostas (PNAIC e Rede Municipal) busca nos encontros formativos dos professores alfabetizadores, atender ao máximo a necessidade de todo o corpo docente e com isso, ter como produto, professores mais bem preparados para atuar em sala de aula, potencializando os resultados em todo o processo de ensino-aprendizagem.

Ações em regime de parceria, em determinadas situações, podem ter na sua execução, tanto potencialidades - pontos positivos, como fragilidades das quais implicam na maioria das vezes no não alcance dos objetivos da ação / metas em sua totalidade, pois podem enfrentar dificuldades, por 
Id on Line Revista Multidisciplinar e de Psicologia

Id on Line Revista Multidisciplinar e de Psicologia

diversas vezes burocráticas e até de cunho logísticos que podem refletir nos resultados. Através da pesquisa bibliográfica de autores que abordam o tema políticas públicas educacionais e da definição das estratégias, além dos documentos bases tanto da Rede Municipal de ensino, quanto os documentos que regem o Programa instituído pelo MEC, pretende-se ao final da pesquisa, responder a questão norteadora e como isso, propor sugestões para a otimização das ações educacionais da Rede de Ensino da qual direcionamos o estudo.

Logo, na necessidade de delimitar o tema, espaço e ação, questiona-se a possibilidade da utilização da ludicidade na alfabetização em uma escola pública municipal. Para isso, é preciso realizar uma revisão bibliográfica sobre estratégias contidas no Plano Nacional da Educação, entender como esses elementos se interagem sob a luz das políticas públicas e realizar uma experiência em uma escola da rede municipal de ensino, na cidade de Juazeiro-BA.

\section{Fundamentação Teórica}

A fundamentação teórica a seguir percorre um trecho que inicia na necessidade de identificação de uma estratégia empresarial para a condução dos trabalhos organizacionais, passando pelo eixo da gestão pública educacional, percorrendo o PNAIC contemplado na alfabetização e letramento, tendo a ludicidade como elemento que fecha o ciclo - sendo esse o fator que materializa o trabalho acadêmico através do relato de experiência.

\section{Estratégias Organizacionais para a Educação}

Como o objetivo geral do trabalho busca, paralelamente, identificar as possibilidades de melhoria do sistema educacional da alfabetização, essa busca, traduzindo para o ambiente acadêmico e de gestão, pode ser tratada como definição da estratégia - que é diferente da palavra planejamento, apesar de muitos as tratarem como a mesma coisa. O planejamento é o preparo para a execução de uma atividade percebendo os recursos e destinando finalidades (TAVARES, 2010).

Já a estratégia é a execução propriamente dita de fatores. Dentre as diversas explanações do que seja estratégia, uma das mais clássicas e utilizadas é a de Wright, Kroll e Parnell (2000), que a define como os planos da alta gestão de uma organização para alcançar resultados, metas e objetivos, diretamente ligados com a missão e visão gerais da organização. Kaplan e Norton (1997) defendem que a estratégia, etapa fundamental de um processo gerencial, movimenta toda a empresa ou instituição, desde a alta gestão até as atividades operacionais que são executadas pela força de trabalho de uma organização. 
Id on Line Revista Multidisciplinar e de Psicologia

Id on Line Revista Multidisciplinar e de Psicologia

Para Mintzberg e Quinn (1991), estratégia pode conter táticas, objetivos, metas, direção, planejamento, políticas, programas, entre outros, numa infinita busca de permitir a realização de um processo funcional através do processamento das ideias de um grupo profissional.

No tocante da definição das diretrizes, algumas metas para a educação foram definidas. O PNE - Plano Nacional de Educação - foi elaborado com esses compromissos, largamente debatidos e apontados como estratégicos pela sociedade na CONAE 2010, os quais foram aprimorados na interação com o Congresso Nacional. Dentre todas as metas presentes no Plano Nacional da Educação (2015) duas se destacam. São:

- Meta 5: alfabetizar todas as crianças, no máximo, até o final do $3^{\circ}$ (terceiro) ano do ensino fundamental.

- Meta 7: fomentar a qualidade da educação básica em todas as etapas e modalidades, com melhoria do fluxo escolar e da aprendizagem[...].

Portanto, é importante uma clara e límpida definição das macro expectativas do poder público e da alta administração em relação ao que deve ser realizado e materializado de forma tática e operacional para atingir essa meta corporativa.

Fomenta-se então, ainda de acordo com o PNE (2015), a valorização ao desenvolvimento de métodos educacionais e de inovação das práticas pedagógicas. Valoriza-se a seleção e divulgação de tecnologias que sejam fatores de melhoria da alfabetização e letramento, favorecendo a aprendizagem dos alunos, sem que se deixe de assegurar a diversidade e pluralidade de formas pedagógicas nos processos de alfabetização.

\section{Políticas Públicas: a arte de realizar ações para a coletividade}

Para início de conversa, é de fundamental importância, antes de tratarmos propriamente da temática desse subcapítulo, conceituarmos na perspectiva das ciências sociais, a definição de sociedade que é um grupo de indivíduos, dotados de interesses, características (cor, sexo, estado civil, escolaridade, renda, idade e etc...) e recursos de poderes diversos, e que por meio da sua interação, satisfazem as suas necessidades. Dentro dessa sociedade, existem interesses e necessidades dos quais gera múltiplas possibilidades e complexidades para a existência na humanidade que podem gerar inúmeras cooperações, competições e até conflitos.

Os conflitos, nesse sentido, podem ser sanados em duas possibilidades: a coerção e a política. A coerção é o ato de reprimir, conter, frear e a política é propriamente a ação exercida pelo Estado 
para a garantia do direito dos cidadãos. No caso da coerção, tem-se um custo e desgaste elevados para quem a aplica e pode-se gerar fortes reações com a aplicação da força.

Assim, a política é buscada com a finalidade seja de controlar conflitos e/ou na construção de consensos. Mas, afinal, o que é a política? Segundo Schmitter (1984), "política é a resolução pacífica para os conflitos". Ainda que esta definição pareça simplista e ao mesmo templo ampla, pode-se afirmar que política, segundo Rua (1998), é um conjunto de ações formais e informais que expressam relações de poder e que se destinam à resolução pacífica dos conflitos quanto a bens públicos.

As políticas públicas nessa perspectiva podem ser entendidas como um conjunto das decisões e ações envolvendo bens públicos e requer inúmeras estratégias para a realização das decisões tomadas, tendo seu caráter irremediavelmente no âmbito público. No subcapítulo a seguir, serão tratadas, dentro da perspectiva das políticas públicas direcionadas a educação, o desafio de alfabetizar e letrar do qual o Programa Pacto destina-se.

No intuito de atingir os objetivos do Programa, de acordo com o MEC:

(...) as ações do Pacto compreendem um conjunto integrado de programas, materiais e referências curriculares e pedagógicas, disponibilizados pelo Ministério da Educação, que contribuem para a alfabetização e o letramento, tendo como eixo principal a formação continuada dos professores alfabetizadores. Essas ações são complementadas por outros três eixos de atuação: materiais didáticos e pedagógicos, avaliações e controle social e mobilização. (BRASIL, Documento orientador Pacto 2014, p 1)

Seguindo essa perspectiva, no que tange as políticas públicas educacionais das quais se pretende refletir dentro dessa pesquisa, a autora Neusa Chaves Batista, afirma na ótica do Estado e Gestão, que:

(...) as políticas públicas sociais no Brasil encontram-se condicionadas, na atualidade, por dois importantes fatores: um de cunho estrutural, que diz respeito à própria formação do Estado brasileiro, o qual estruturou os sentidos, valores e crenças da própria sociedade por meio de redes de significações de cunho autoritárias. Essas representações se fazem presentes em nosso sistema de dominação, atribuindo significados à definição social da realidade e, consequentemente, orientando os processos de decisão, formulação e implementação das políticas. (BATISTA, 2007, p 398)

Nestes termos, as políticas públicas segundo a autora, passam por diversos entraves historicamente construídos e que tem consequências até os dias atuais no direcionamento dessas políticas de cunho reparatório quanto aos déficits sociais acumulados até os dias atuais.

\section{Alfabetização e Letramento: Desafios do PNAIC}


Id on Line Revista Multidisciplinar e de Psicoloqia

Id on Line Revista Multidisciplinar e de Psicologia

A alfabetização historicamente, é sem dúvidas um grande entrave em se tratando do processo de ensino-aprendizagem. Cada indivíduo no uso de (re) construção de estratégias e hipóteses, vai delineando essa trajetória na sua vida escolar.

Nesse sentido, inúmeros estudos e pesquisas, foram criados a fim de auxiliar a comunidade escolar (pais, professores, gestores, coordenadores pedagógicos) nessa caminhada. Ferreiro (1997) ao abordar o ensino da leitura e sua metodologia discorre:

Tradicionalmente, conforme uma perspectiva pedagógica, o problema da aprendizagem da leitura e da escrita tem sido exposto como uma questão de métodos. A preocupação dos educadores tem-se voltado para a busca do "melhor" ou "mais eficaz" deles, levantando-se, assim, uma polêmica em torno de dois tipos fundamentais: métodos sintéticos, que partem de elementos menores que a palavra, e métodos analíticos, que partem da palavra ou de unidades maiores. Em defesa das respectivas virtudes de um e de outro, originou-se uma discussão registrada em extensa literatura; literatura que tanto faz referência a aspecto metodológico em si como aos processos psicológicos subjacentes. Recordemos, primeiro, qual é o enfoque didático para, em seguida, insistirmos nos supostos psicológicos relativos aos métodos, assim como às concepções - implícitas ou explícitas - sobre o processo da aprendizagem. (FERREIRO, 1997, p. 21)

Assim, as metodologias que ao longo das décadas foram sendo criadas, não mais, dentro de tantas mudanças sócio históricas, dão conta de manter-se as mesmas, sendo necessário ajustes que levem a construção de ações que facilitem o processo de ensino-aprendizagem, tendo como produto disso, cidadãos alfabetizados e capazes de criticamente, contribuir na nossa sociedade, ou seja, educandos letrados, como define Magda Soares, o letramento "como condição de quem não apenas sabe ler e escrever, mas cultiva e exerce as práticas sociais que usam a escrita" (SOARES, 2000, p. 47).

Sendo a Alfabetização e o letramento, portanto, desafios a vencer com ações que vem sedo executadas pelo MEC desde 2013 em regime de parceria com Estados, IES e Municípios com a implementação do PNAIC para o alcance do maior número de crianças até os oito anos de idade, capazes de interagirem com diferentes suportes de leitura e escrita.

Pensar no tema "Alfabetização" nos remete a uma série de questões que permeiam esse campo educacional. Sabemos que são muitos os desafios encontrados pelos professores alfabetizadores em sala de aula tanto em relação ao que é ensinado como em relação a como é ensinado. É grande a preocupação dos governos, federais, estaduais e municipais em relação a esse processo educacional tão fundamental e necessário no inicio da vida escolar das crianças.

O Ministério da Educação - MEC em consonância com os governos conferiu no ano de 2012 a medida provisória $\mathrm{n}^{\circ} 586$ que determina a formação continuada de professores alfabetizadores, com o objetivo de apoiar esses profissionais que atuam nesse ciclo educacional, a planejarem as suas aulas 
Id on Line Revista Multidisciplinar e de Psicoloqia

Id on Line Revista Multidisciplinar e de Psicologia

utilizando-se de métodos que articulem os meterias e as referencias curriculares pedagógicas disponibilizadas pelo MEC.

De acordo com a portaria do Ministério da Educação, essa proposta de formação continuada de professores alfabetizadores, utilizaria de materiais próprios que seriam fornecidos pelo MEC a todos os orientadores de estudo (formadores), e professores alfabetizadores cursistas. Para compreender melhor o processo educacional, é importante observar alguns direcionamentos legais, a Constituição Federal em seu artigo traz a finalidade da educação:

A educação direito de todos e dever do estado e da família, será promovida e incentivada com a colaboração da sociedade, visando ao pleno desenvolvimento da pessoa, seu preparo para o exercício da cidadania e sua qualificação para o trabalho. (BRASIL. Constituição da República Federativa do Brasil, 1988).

A LDB, Art. $2^{\circ}$ afirma que:

A educação, dever da família e do estado, inspirada nos princípios de liberdade e nos ideais de solidariedade humana, tem por finalidade o pleno desenvolvimento do educando, seu preparo para o exercício da cidadania e sua qualificação para o trabalho. (LDB, 1996).

Ainda de acordo com o MEC, dentro da normativa lançada em $2012^{1}$, essas formações seriam ofertadas de forma presencial com duração de duzentas horas anuais, incluindo as atividades extraclasses para os orientadores de estudo e cento e vinte horas, incluindo as atividades à distância para os professores alfabetizadores. Ainda segundo o MEC, essa formação continuada seria ofertada por instituições de ensino superior que seriam definidas pelo Ministério, oferecida aos orientadores de estudo que, por sua vez são responsáveis pela formação dos professores alfabetizadores, em cada Rede Municipal de Ensino.

É importante dar ênfase também ao papel da escola e do professor alfabetizador, que tem sob sua responsabilidade a função de embasar, criar um alicerce na vida dessas crianças para que essas possam prosseguir na sua jornada acadêmica de forma consistente e segura. É notória a importância da relação família-escola no processo de ensino aprendizagem dos educandos.

O Pacto Nacional pela Alfabetização na Idade Certa (PNAIC) é um acordo formal assumido pelos governos federal, Distrito Federal, estados e municípios, e tem como objetivo alfabetizar todas as crianças, até os oito anos de idade, ou seja, até o fim do $3^{\circ}$ ano do Ensino Fundamental. Analisando o PNAIC é possível identificar quatro princípios centrais, que precisam ser considerados no desenvolvimento e na organização da prática pedagógica, entre eles destacamos:

\footnotetext{
${ }^{1}$ Nos anos subsequentes de execução do PNAIC, a carga horária de Formação presencial e atividades à distância, foi gradativamente ampliada, partindo da necessidade sinalizada através das ações desenvolvidas. 
1. O Sistema de Escrita Alfabética é complexo e exige um ensino sistemático e problematizador;

2. O desenvolvimento das capacidades de leitura e de produção de textos ocorre durante todo o processo de escolarização, mas deve ser iniciado logo no início da Educação Básica, garantindo acesso precoce a gêneros discursivos de circulação social e a situações de interação em que as crianças se reconheçam como protagonistas de suas próprias histórias;

3. Conhecimentos oriundos das diferentes áreas podem e devem ser apropriados pelas crianças, de modo que elas possam ouvir, falar, ler, escrever sobre temas diversos e agir na sociedade;

4. A ludicidade e o cuidado com as crianças são condições básicas e nos processos de ensino e de aprendizagem. (BRASIL, PNAIC 2012).

Tendo como alicerce estes quatros princípios, o objetivo deste programa, é proporcionar aos alunos do $1^{\circ}$ ao $3^{\circ}$ ano do Ensino Fundamental, um processo de alfabetização de qualidade, que vise a construção e o exercício da cidadania. Desta forma, entende-se a importância do professor alfabetizador ter clareza em seus objetivos educacionais, visto que ele não é um mero transmissor de conhecimento e de saberes, e sim, tem o papel de conduzir os alunos na construção do conhecimento, no processo de ensino-aprendizagem e no desenvolvimento integral, proporcionando ambientes de aprendizagem, que sejam significativos para os alunos e que contribuam para o seu processo de alfabetização.

De acordo com Ferreiro (2011, p.48) "a alfabetização não é um estado ao qual se chega, mas um processo cujo inicio é, na maioria dos casos, anterior à escola e que não termina ao finalizar a escola primária." Desta forma é possível compreender que a alfabetização é um processo permanente e contínuo, pois não se acaba na aprendizagem da leitura e da escrita. Este processo permeia e acontece no decorrer da vida, pois no dia a dia já possuímos um contato com o mundo escrito, com a leitura, elaborando assim hipótese para compreender a escrita. Com isso é possível observar a importância de se utilizar instrumentos que permitam atividades lúdicas no processo de alfabetização, pois o brincar faz parte tanto do espaço escolar, como dos espaços extra escolares. Desta forma, é possível realizar uma relação entre o cotidiano do aluno e as vivências dele no mundo da escrita e assim, enriquecer o processo de alfabetização na escola. Portanto, o lúdico auxilia no processo de vinculação entre a realidade vivida e os saberes escolares.

\section{A Ludicidade como alternativa na Prática Docente}

A ludicidade se faz muito importante no processo de ensino-aprendizagem, pois tem o poder de ativar a capacidade dos alunos para que eles descubram um modo eficiente, dinâmico e divertido de aprender a aprender. A formação lúdica, para Kishimoto (1999), possibilita ao educador conhecer-se como pessoa, saber de suas possibilidades, desbloquear resistências e ter uma visão clara sobre a importância do jogo e do brinquedo para a vida da criança, do jovem e do adulto. Ludicidade, portanto, é quando nos utilizamos dos jogos, brinquedos e brincadeiras visando possibilitar um 
Id on Line Revista Multidisciplinar e de Psicoloqia

Id on Line Revista Multidisciplinar e de Psicologia

ambiente de aprendizagem mais enriquecedor e prazeroso, tanto para as crianças quanto para os professores.

Segundo Antunes (1999), nem todo jogo é um material pedagógico. Isso significa dizer que os jogos e alguns brinquedos pedagógicos não podem ser usados somente em caráter lúdico de brincar por brincar, é preciso ter um objetivo, uma intenção com o uso desses instrumentos, os brinquedos e brincadeiras pedagógicas precisam ser desenvolvidos com a intenção de despertar na criança a construção de um novo conhecimento e provocar uma aprendizagem significativa.

A palavra lúdico vem do latim ludus e significa brincar. Neste brincar estão inclusos os jogos, brinquedos e outras brincadeiras e é relativa também à conduta daquele que joga, que brinca e que se diverte. Sendo assim, a função educativa do jogo oportuniza a aprendizagem do indivíduo, seu saber, seu conhecimento e sua compreensão de mundo.

Para Antunes (1999), está se perdendo no tempo a época em que se separava a "brincadeira", jogo pedagógico, da atividade "séria". Assim, ainda para o autor, brincar significa extrair da vida nenhuma outra finalidade que não seja ela mesma. Em síntese, o jogo é o melhor caminho de iniciação ao prazer estético: é descoberta da individualidade e à meditação individual.

Faz-se necessário o respaldo do autor em relação ao como brincar, pois a brincadeira no ambiente escolar tem que ter significado. É preciso oportunizar as crianças brincadeiras nas quais elas possam desenvolver habilidades como, criatividade, autonomia, imaginação e, sobretudo, o trabalho em grupo.

\section{Método Científico}

O investigador na perspectiva da pesquisa descritiva necessita de informações diversas acerca do objeto de estudo / pesquisa. O referido estudo busca descrever acontecimentos e fenômenos de determinada situação (TRIVIÑOS, 1987). Pode-se citar como exemplos de pesquisa descritiva a análise documental e estudo de caso. De acordo ainda com o autor, as técnicas empregadas para a coleta de dados são subjetivas, tendo como premissa a quantificação.

A pesquisa a ser aplicada tem seu Estudo de Campo na Rede Municipal de Ensino de Juazeiro - BA, tendo a metodologia empregada no seu desenvolvimento, em cinco momentos distintos:

a) Estudo bibliográfico acerca da temática tendo com principais fontes os autores: Ferreiro (1999), Rua (2009) e Soares (2000);

b) Levantamento dos dados obtidos no processo de análise e observação participativa;

c) Análise dos dados através de relato de experiência; 
Id on Line Revista Multidisciplinar e de Psicoloqia

Id on Line Revista Multidisciplinar e de Psicologia

Para Gil (2007), a modalidade estudo de caso é amplamente usada nas ciências biomédicas e sociais. A referida pesquisa tem características de instituições bom organizadas, a exemplo de um programa, uma escola, uma pessoa, e uma organização social. Busca descobrir as causas de determinadas situações e suas especificidades. $\mathrm{O}$ investigador nesse caso, não intervém sobre o objeto de estudo, entretanto mostra-o fidedignamente sobre o seu olhar/ interpretação, e ao mesmo tempo compreende o ponto de vista dos envolvidos no processo, de maneira coerente e global. (FONSECA, 2002).

Para Alves-Mazzotti (2006), o estudo mais comum é o que focaliza apenas um indivíduo, um pequeno grupo, uma instituição, um programa ou um acontecimento. Ainda de acordo com a autora existem também os casos múltiplos, em que vários estudos com vários indivíduos ocorrem ao mesmo tempo, a exemplo de professores alfabetizadores com ações exitosas ou o caso de estabelecimentos de ensino que estão desenvolvendo o mesmo programa, a exemplo do PNAIC.

Quanto aos meios, a mesma é uma pesquisa de campo, pois são aplicados instrumentos avaliativos da política pública educacional, bibliográfica, e são utilizados como fonte de pesquisa, os estudos já realizados na área das Políticas públicas, na área educacional (Formação continuada, Alfabetização e letramento, relações de ensino-aprendizagem), e a pesquisa documental, através dos documentos que regem a Educação tanto a nível federal, quanto a nível municipal, além dos registros já realizados por professores e equipe de formação do Pacto.

\section{Análise da observação sistemática a partir da prática docente na cidade de Juazeiro-BA}

Juazeiro - BA ${ }^{2}$ localizada na região do Vale do São Francisco, com área de 6454,25 km² e um IDHM 2010 de 0,677, sendo que o IDHM médio é entre 0,6 e 0,699. Possui uma população de Acordo com o Censo 2010 de 197.965 habitantes e densidade demográfica de 30,67 hab/km². O município está situado na faixa de Desenvolvimento Humano Médio (IDHM entre 0,6 e 0,699). Entre 2000 e 2010, a dimensão que mais cresceu em termos absolutos foi a Educação (com crescimento de 0,225), seguida por Longevidade e por Renda. Entre 1991 e 2000, a dimensão que mais cresceu em termos absolutos também a Educação (com crescimento de 0,157), seguida por Longevidade e por Renda.

Nessa perspectiva, segundo a proposta formativa, o Pacto Nacional pela Alfabetização na Idade Certa é um acordo formal assumido pelo Governo Federal, estados, municípios e entidades para firmar o compromisso de alfabetizar crianças até, no máximo, 8 anos de idade, ao final do ciclo de alfabetização (Caderno de Apresentação - PNAIC, p 1).

\footnotetext{
${ }^{2}$ Os dados basearam-se na pesquisa realizada nas fontes de dados do PNUD - Programa das Nações Unidas para o Desenvolvimento, IPEA - Instituto de Pesquisa Econômica Aplicada e FJP - Fundação João Pinheiro. 
Na busca da reparação desses déficits sociais e em sintonia com o PNAIC, a Rede Municipal de Ensino de Juazeiro - BA, em sua proposta de Formação continuada, pensa que o processo formativo, dentro das ações de políticas públicas voltadas a educação, vai:

(...) construindo e desconstruindo conceitos para com isso, dialogar com novos saberes essenciais ao desenvolvimento subjetivo e profissional dos professores. Portanto, a formação pode ser considerada como parte de um projeto pessoal, uma escolha significativa por dar sentido e valor ao fazer pedagógico docente" (Proposta de Formação Continuada da Rede 2013).

Nesse sentido, a pesquisa apresentada, buscou analisar a efetivação do PNAIC na Rede Municipal de Ensino da citada cidade, os seus progressos e fragilidades, frente aos objetivos do Programa a nível federal na sua execução, no âmbito da Gestão Pública.

É importante destacar a contribuição do PNAIC e do PNE para qualificação e aprimoramento da prática pedagógica e da ação como docente. Com esta proposta de formação continuada para os professores alfabetizadores, que atuam no ciclo de alfabetização $\left(1^{\circ}\right.$ ao $3^{\circ}$ ano do Ensino Fundamental), o PNAIC, influenciou fortemente as práticas pedagógicas desenvolvidas no contexto escolar, pois a partir deste programa, puderam ser desenvolvidas outras possibilidades para que o processo de ensino-aprendizagem seja realmente significativo, criando com isso, outras tantas possibilidades para realização em sala de aula, em prol do desenvolvimento cognitivo da criança. Foram criados cantinhos da leitura, oportunizando momentos de interação com os livros e de desenvolvimento da imaginação a partir deles, momentos lúdicos, experiências com jogos e principalmente atividades práticas, com materiais concretos. Para isso acontecer com qualidade, o professor necessitou ter clareza sobre como e o que ensinar, para assim, contribuir no processo de alfabetização dos alunos, de uma maneira significativa e divertida, tornando assim, todos ativos na construção do conhecimento.

O Pacto Nacional pela Alfabetização na Idade Certa (PNAIC) influenciou fortemente a ação docente. Esta influência contribuiu de maneira significativa e positiva, para as práticas pedagógicas, pois o PNAIC proporciona uma formação continuada para o professor e alfabetizador. Isto por que:

Não há ensino sem pesquisa e pesquisa sem ensino. Enquanto ensino contínuo buscando, reprocurando. Ensino porque busco, porque indaguei, porque indago e me indago. Pesquiso para constatar, constatando, intervenho, intervindo educo e me educo. Pesquiso para conhecer o que ainda não conheço e comunicar ou anunciar a novidade. (FREIRE, 2009, p.29)

O estudo, bem como sua compreensão e entendimento, intensificaram e tornaram-se fortes elementos, no desenvolvimento de estratégias docentes . Depois do Pacto Nacional Pela Alfabetização na Idade Certa, os pesquisadores puderam repensar suas práticas pedagógicas e cotidianamente inserir e envolver a ludicidade as atividades desenvolvidas em sala de aula. As atividades com jogos foram 
intensificadas, (alfabeto móvel, bingos de letras, palavras, sílabas, números e operações), tornando assim o processo de ensino-aprendizagem e de alfabetização, muito mais significativo e divertido, suprindo as dificuldades dos alunos e os auxiliando na construção do conhecimento. A partir da metodologia lúdica, percebeu ainda que os alunos, à medida que brincavam, se envolviam mais em sua aprendizagem e se tornavam mais ativos em seu desenvolvimento.

Desta forma, a aprendizagem com jogos e com uma metodologia lúdica, torna os alunos mais participativos, pois as atividades são relacionadas com o cotidiano dos mesmos. Conforme Sacristán (2007, p. 97) "toda aprendizagem relevante é no fundo um processo de diálogo com a realidade social e natural ou com a imaginada." Entretanto, a aprendizagem é um diálogo entre a sociedade, os conhecimentos prévios que os sujeitos possuem com os conhecimentos científicos.

É importante frisar que os jogos tem um grande papel no processo da alfabetização, pois trazem grandes contribuições, sendo necessária também, a fundamentação teórica para motivar a prática pedagógica. Desta forma, é preciso estar pesquisando constantemente a fim de aperfeiçoar os conhecimentos em relação ao processo de alfabetização. Buscando assim, compreender os níveis de escrita dos alunos, para planejar as atividades de forma que auxiliem e contribuam para o seu avanço, sem deixar de lado esse fator importante: os diferentes níveis de escrita próprios de cada sala de aula, sendo, portanto, o planejamento de suma prioridade, no sentido de atender aos educandos, cada um dentro da sua necessidade.

Para verificar os níveis de aprendizagens dos alunos, são aplicados mensalmente, diagnósticos, que permitem avaliar o desenvolvimento de cada aluno. Esses diagnósticos são realizados com base nos conteúdos vivenciados em sala de aula, em consonância com a Proposta Curricular da Rede Municipal de Ensino de Juazeiro - BA. Desta forma, as avaliações ocorrem de maneira processual, pois diariamente os alunos são avaliados. Reforçando Libâneo (1994), quando afirma que:

\begin{abstract}
A avaliação é uma tarefa didática necessária e permanente do trabalho docente, que deve acompanhar passo a passo o processo de ensino e aprendizagem. Através dela, os resultados que vão sendo obtidos no decorrer do trabalho conjunto do professor e dos alunos são comparados com os objetivos propostos, a fim de constatar progressos, dificuldades, e reorientar o trabalho para as correções necessárias. (LIBÂNEO, 1994, p.195)
\end{abstract}

Além das atividades continuadas, os diagnósticos são utilizados tanto para avaliar o desempenho dos alunos ${ }^{3}$, como para a professora da turma, realizar o processo de reflexão de sua

\footnotetext{
${ }^{3}$ Desde 2010, a Rede Municipal de ensino de Juazeiro BA, possui uma política de acompanhamento diagnóstico por bimestre em Língua Portuguesa e Matemática, em que eram por sua vez, enviadas pela Rede às Instituições escolares. No ano de 2013, foi instituído às Escolas da Rede municipal, a elaboração do diagnóstico de início do bimestre letivo (diagnóstico de entrada), e a Secretaria de Educação, por sua vez, ficou sob a incumbência de elaborar diagnósticos de consolidação do bimestre (Diagnóstico de saída). Após aplicação dos diagnósticos (Entrada e saída do bimestre), os professores inserem os dados em planilha elaborada pela Rede, considerando os eixos de Língua Portuguesa: Leitura, Escrita e produção de Texto e os eixos de Matemática: números e operações, espaço e forma, 
Id on Line Revista Multidisciplinar e de Psicologia

Id on Line Revista Multidisciplinar e de Psicologia

própria prática, traçando através dos resultados obtidos, ações de cunho interventivo junto às dificuldades encontradas no processo de ensino-aprendizagem. Ao serem realizados esses diagnósticos, notamos a evolução dos alunos em relação à leitura escrita. Segundo Emília Ferreiro e Ana Teberosky (1985), as crianças no processo evolutivo de aprender a ler e escrever, passam por diferentes níveis, que revelam quais são as hipótese que constroem sobre a língua escrita. No início do ano, geralmente, a grande maioria dos alunos encontram-se na hipótese pré-silábica, e no decorrer do ano letivo a meta é que cada um vá avançando até ao final do ciclo chegar ao nível alfabético, lendo e escrevendo com autonomia e desprendimento.

\section{Conclusão}

O Pacto Nacional pela Alfabetização na Idade Certa (PNAIC) é um acordo formal assumido pelo governo federal, Distrito, estados e municípios, e tem como objetivo alfabetizar todas as crianças, até os oito anos de idade, ou seja, até o fim do $3^{\circ}$ ano do Ensino Fundamental.

A pesquisa realizada em detrimento às ações propostas pelo PNAIC, e executadas pela Rede Municipal de Educação em Juazeiro - BA nos mostram um resultado positivo, levando-se em consideração a importante ferramenta estratégica da ludicidade no processo de ensino-aprendizagem, alcançando assim, o objetivo geral do estudo, bem como os objetivos específicos que incluíram a revisão bibliográfica com foco no Plano Nacional de Educação e como os entendimentos de como esses elementos interagem sob a luz das políticas públicas e a realização da experiência em uma Escola da Rede Municipal de Ensino na cidade de Juazeiro BA, dentro da temática em questão.

Através da pesquisa de campo, exposta no relato de experiência, foi percebida que a utilização das estratégias que envolvem a ludicidade, a exemplo dos jogos, atividades e brincadeiras pedagógicas, que exercem um importante papel, no sentido de facilitar a aprendizagem dos educandos e torná-la mais significativa, pois a ludicidade se faz muito importante no processo de ensinoaprendizagem, tendo esta, o poder de ativar a capacidade dos alunos para que eles descubram um modo eficiente, dinâmico e divertido de aprender a aprender.

Nesse sentido, sugere-se a potencialização das ações lúdicas dentro do Planejamento das atividades diárias do professor na própria escola, campo de pesquisa, nas séries iniciais do $1^{\circ}, 2^{\circ}$ e $3^{\circ}$ ano, e inclusive, nos outros anos/séries e modalidades que não se incluem no PNAIC. Sugere-se ainda, que as outras Instituições educacionais da Rede Municipal, que não adotam essa importante estratégia,

grandezas e medidas, tratamento da informação. Após o lançamento desses dados no SIEM - Sistema de Informações da Educação Municipal, existe a consolidação, por turma, escola e município, e direcionadas as devidas intervenções quanto aos resultados obtidos, como forma de contribuir de maneira concreta no processo de ensino - aprendizagem da referida Rede Educacional. 
Id on Line Revista Multidisciplinar e de Psicoloqia

Id on Line Revista Multidisciplinar e de Psicologia

passem a realizá-la, para que com isso, ocorra uma aprendizagem mais significativa e consequentemente, de qualidade.

\section{Referências}

ANTUNES, Celso. Jogos para a estimulação das múltiplas inteligências. 3 ed. Petrópolis: Vozes, 1999.

ALVES-MAZZOTTI, A. J.; GEWANDSZNAJDER, F. Usos e abusos dos estudos de caso. Cadernos de Pesquisa (online), v. 36, n. 129, p. 637-51, 2006.

BATISTA, Neusa Chaves. A formação do Estado nacional brasileiro: implicações para a gestão das políticas públicas educacionais. Eccos Revista Científica, vol. 9, núm. 2, julho-dezembro, pp. 387408, Universidade Nove de Julho. Brasil, 2007.

BRASIL. Lei $\mathbf{n}^{\mathbf{0}}$ 9.394/1996. Estabelece as Diretrizes e Bases da Educação Nacional. DOU 23.12.1996.

BRASIL. Constituição da República Federativa do Brasil. Brasília, DF: Senado, 1988. (Disponível em: http://www.planalto.gov.br/ccivil 03/constituição)ConstituiçãoCompilado.htm. Acesso em 16 mai 2016.

BRASIL. Documento Orientador Pacto 2014. Coordenação de Formação Continuada de Professores. - Brasília: DAGE/SEB/MEC, 2014.

BRASIL. PNAIC - Pacto Nacional pela alfabetização na Idade Certa: Caderno de apresentação. Ministério da Educação, Secretaria de Educação Básica. Diretoria de Apoio à Gestão Educacional, Brasília: MEC, SEB, 2012.

FERREIRO, Emilia; Teberosk, Ana. A Psicogênese da Língua Escrita. Porto Alegre: Artes Medicas 1985. 284p.

FERREIRO, Emília. Psicogênese da língua escrita / Emília Ferreiro, Ana Teberosky; tradução Diana Myriam Lichtenstein. Liana Di Marco, Mário Corso. ---- Porto Alegre: Artmed, 1999.

FONSECA, J. J. S. Metodologia da pesquisa científica. Fortaleza: UEC, 2002. Apostila.

FREIRE, P. Pedagogia da Esperança: um reencontro com a Pedagogia do Oprimido. Rio de Janeiro: Paz e Terra. $16^{\text {a }}$ ed. 2009.

GIL, A. C. Como elaborar projetos de pesquisa. 4. ed. São Paulo: Atlas, 2007.

KAPLAN, Robert S., NORTON, David P. A Estratégia Em Ação: The Balanced Scorecard. Rio de Janeiro: Campus, 1997.

KISHIMOTO, Tizuko M. Jogos infantis: o jogo, a criança e a educação. Petrópolis, RJ: Vozes, 1993.

LIBÂNEO, José Carlos. Didática. 13 Ed. São Paulo: Cortez, 1994. 
Id on Line Revista Multidisciplinar e de Psicoloqia

Id on Line Revista Multidisciplinar e de Psicologia

MINTZBERG, H.; QUINN, J. B. The Strategy Process: Concepts, Contexts and Cases. 2. ed. Englewood Cliffs: Prentice-Hall International, Inc., 1991.

PNE - Plano Nacional da Educação: Planejando a Próxima Década Conhecendo as 20 Metas do Plano Nacional de Educação. 2015. Presidência da República, Ministério da Educação, Secretaria de Articulação com os Sistemas de Ensino. Disponível em http://pne.mec.gov.br/images/pdf/pne_conhecendo_20_metas.pdf. Acesso em 28/05/2016.

RUA, Maria das Graças. Análise de Políticas Públicas: Conceitos Básicos. In: RUA, Maria das Graças;VALADAO, Maria Izabel. O Estudo da Política: Temas Selecionados. Brasília: Paralelo 15, 1998.

SACRISTÁN, J. G. A educação que ainda é possível: ensaios sobre uma cultura para a educação. Porto Alegre: Artmed, 2007.

SCHMITTER, Phillip. Reflexões sobre o Conceito de Política. In: BOBBIO, Norberto et al. Curso de Introdução à Ciência Política. Brasília: UnB, 1984.

SEDUC. Secretaria Municipal de Educação do Município de Juazeiro - BA. Proposta de Formação Continuada. PMP - Prefeitura Municipal - Juazeiro, 2013.

SOARES, Magda. Letramento: um tema em três gêneros. Belo Horizonte: Autêntica, 2000.

TAVARES, M. C. Gestão Estratégica. 3ª ed. São Paulo: Atlas. 2010.

TRIVIÑOS, A. N. S. Introdução à pesquisa em ciências sociais: a pesquisa qualitativa em educação. São Paulo: Atlas, 1987.

WRIGHT, P.; KROLL, M.; PARNELL, L. Administração estratégica: conceitos. São Paulo: Atlas, 2000. ZACCARELLI, S. B. A moderna estratégia nas empresas e o velho planejamento estratégico, RAE Light, São Paulo: FGV.

Como citar este artigo (Formato ABNT):

SANTOS, G.G.; CAFFÉ, L.S.R.; CEFFÉ FILHO, H.P. A Ludicidade como importante Estratégia de Ensino no Pacto Nacional pela Alfabetização na Idade Certa (PNAIC) em Juazeiro - BA. Id on Line Revista Multidisciplinar e de Psicologia, Julho de 2016, vol.10, n.30. p. 53- 67. ISSN 1981-1179.

Recebido: $22 / 05 / 2016$

Aceito: $31 / 05 / 2016$ 